\title{
"As mulheres são maioria nos cursos e isso faz com que mais e mais mulheres entrem no mercado de trabalho, mas essa entrada não é totalmente igualitária, infelizmente"
}

Ligia Tesser Pereira'

Maria José Braga é presidenta da Federação Nacional dos Jornalistas (Fenaj) e estará à frente da entidade até 2022, além de integrar o GT Comunicadores pelo conselho Nacional de Defesa dos Direitos Humanos. Maria José é formada em Jornalismo e em Filosofia pela Universidade Federal de Goiás (UFG) e mestre em Filosofia pela mesma instituição de ensino. Atualmente é repórter do jornal $O$ Popular e jornalista do Instituto Federal de Educação, Ciência e Tecnologia.

Com experiência na atuação em entidades de representação profissional, Maria José já foi vice-presidenta da Fenaj, além de secretária-geral, tesoureira e vice-presidenta da Região Centro-Oeste. A jornalista esteve em Ponta Grossa (PR), em abril de 2019, quando participou do 6을 Colóio Mulher e Sociedade. Na oportunidade, dividiu a mesa de debates com Nadia Kovaleski (UFPR) e Ananda Puchta (OAB/PR e Coletivo Cássia), no painel "Relações de gênero e lutas pela igualdade: Trabalho, ciência e diversidade".

O 6ำ Colóquio Mulher e Sociedade é organizado pelo Grupo de Pesquisa Jornalismo e Gênero, vinculado ao Programa de Pós-Graduação (Mestrado) em Jornalismo da Universidade Estadual de Ponta Grossa (UEPG). O evento é bianual e realizado em parceria com o projeto de extensão Elos - Direitos Humanos, Jornalismo e Formação Cidadã e pelo Departamento de Jornalismo.

Em 2019, o colóquio propôs discutir a temática "Mulheres e Redes: perspectivas de pesquisa e intervenção em gênero". Com a participação da jornalista Maria José Braga

\footnotetext{
1 Possui graduação em Comunicação Social pela Faculdade de Pato Branco (2011). Mestranda no Programa de Pós-Graduação (Mestrado) em Jornalismo da Universidade Estadual de Ponta Grossa (UEPG), bolsista Capes. Membro do Grupo de Pesquisa em Jornalismo e Gênero.
} 


\section{REVISTA PAUTA GERAL}

\section{ESTUDOS EM JORNALISMO}

10.5212/RevistaPautaGeral.v.6.i2.00014

no evento foi possível realizar esta entrevista, em que ela reflete sobre a condição atual da jornalista mulher no mercado profissional.

O jornalismo na contemporaneidade é marcado por diversas questões que afetam diretamente a mulher jornalista, como a crise no mercado do trabalho, assédios no ambiente profissional e nas relações com as fontes, o enxugamento das redações, as mudanças tecnológicas constantes, entre outras. Assim, Maria José traz sua visão como jornalista, mulher e também a partir da direção da principal associação de profissional da categoria no país.



Maria José Braga (MJB): Para nós, essa colocação da mulher no jornalismo se deu a partir da regulamentação da profissão e, principalmente, da exigência da formação de nível superior para o exercício profissional. Como eu disse, isso possibilitou que as mulheres entrassem no jornalismo, mulheres que foram para as universidades, concluíram seus cursos de graduação e puderam buscar trabalho no mercado. As mulheres são maioria nos cursos de jornalismo, isso já tem mais de uma década, não é um fenômeno recente. As mulheres são maioria nos cursos e isso faz com que mais e mais mulheres entrem no mercado de trabalho, mas essa entrada não é totalmente igualitária, infelizmente. As assimetrias de gênero também ocorrem no mercado profissional dos jornalistas e de que forma? Principalmente pela hierarquia, nas grandes redações, que hoje já nem são tão grandes assim, as mulheres ocupam menos postos de chefia. Nós estamos na base do trabalho e os homens continuam ascendendo aos postos de chefia com mais frequência do que as mulheres. Há algumas áreas do jornalismo em que as mulheres ainda têm menor inserção mesmo sendo maioria, por exemplo: na reportagem e no jornalismo de imagem. As mulheres, no que nós classificamos como jornalismo de imagem, são poucas. O que nós chamamos de jornalismo de imagem é o repórter cinematográfico, o repórter fotográfico, o pessoal da diagramação e na área de arte, tanto o que nós chamamos de ilustração, que o 


\section{REVISTA PAUTA GERAL}

\section{ESTUDOS EM JORNALISMO}

10.5212/RevistaPautaGeral.v.6.i2.00014

grande foco hoje no jornalismo são os infográficos, as páginas que mesclam imagem e informação textual. Então, nessas áreas de imagem as mulheres ainda são uma minoria muito significativa.

Pauta Geral (PG): Existem algumas áreas que tradicionalmente eram dadas mais como masculinas dentro do jornalismo como, por exemplo, a cobertura de economia, cobertura de esporte ou até mesmo de política. Como você tem visto esse cenário atualmente?

MJB: Continua! Principalmente o esporte, porque no Brasil a cobertura esportiva jornalística infelizmente está muito focada no futebol profissional, e, no futebol profissional, não temos dados específicos, mas a observação prática, a observação cotidiana, é de que os homens ainda são maioria. Na economia também, com um pouquinho de modificação, porque as mulheres entraram nessas áreas, tanto na economia quanto na política, mas no jornalismo esportivo prevalece e eu creio que por uma que eu chamaria de deficiência desse jornalismo esportivo que está praticamente focado no futebol profissional. Quando as mulheres vão para 0 jornalismo esportivo, normalmente, elas ficam naquela cobertura varejista dos outros esportes, que existem, mas não é o fundante do jornalismo esportivo que continua sendo o futebol.

Pauta Geral (PG): Você comentou sobre essa assimetria que existe em relação a cargos dentro das redações ou de médio/grande porte. Como você vê isso refletindo na questão do salário das jornalistas mulheres? Tem um impacto na renda das jornalistas?

MJB: Sim. Por conta dessa hierarquia. As mulheres com menos cargos de chefia, na média, ganham menos que os homens, isso não se dá na ocupação do mesmo cargo, felizmente. Porque ainda tem algumas profissões que mesmo na ocupação do mesmo cargo as mulheres ganham menos, mas se dá além da hierarquia nas chamadas carreiras empresariais, pois muitas vezes nessa carreira empresarial - por conta da gestão ser masculinas - as mulheres são prejudicadas e os homens ascendem, não só aos cargos, mas também nessa carreira de cargos e salários que as empresas estabelecem; aí essa assimetria para a mesma função aparece. Então, se têm empresas, por 


\section{REVISTA PAUTA GERAL}

\section{ESTUDOS EM JORNALISMO}

10.5212/RevistaPautaGeral.v.6.i2.00014

exemplo, uma mulher vai ficar como repórter nível 01 a vida inteira e um homem chega e ascende para repórter nível 02, nível 03 e dependendo da carreira, nível 04 e etc, com mais facilidade e com maior rapidez.

Pauta Geral (PG): Em relação à ocupação das mulheres, já que somos a maior parte nos cursos de jornalismo, provavelmente ocupamos a maior parte da reportagem, nos primeiros níveis da reportagem. Qual a sua percepção sobre a rotina de trabalho jornalístico vivenciado pelas mulheres e sobre a divisão do trabalho?

MJB: O trabalho geral jornalístico já era exaustivo antes, porque, principalmente, quem é repórter tem aquela concepção de que é repórter em tempo integral, mesmo com as cinco horas, mesmo vocês estando no seu local de trabalho por um período determinado. O repórter é um observador da sociedade e dos fatos, então ele está sempre atento a essa realidade que o envolve. Isso faz com que o jornalismo seja uma profissão de alto grau de stress e já era assim no passado com a "evolução tecnológica", e, principalmente, mesmo os veículos tradicionais também utilizando as plataformas digitais, isso ficou ainda mais evidente. Agora, o repórter sai pra rua, mas ele tem que mandar flash de áudio ou de vídeo pra constar no portal, mesmo quando é um repórter de impresso. repórter de televisão e de rádio já fazia isso com mais frequência. Em razão do telefone, o rádio sempre teve essa imediaticidade muito presente e isso tem feito com que o profissional tenha um desgaste maior e, claro, com maior permanência nas redações. Os repórteres permanecem muito nas redações e os chefes também, então nesse caso há uma dinâmica na produção jornalística que faz com que determinados profissionais, e aí estão incluídos os chefes tenham que pretensamente supervisionar todo 0 processo que está a ele subordinado; isso faz com que o profissional trabalhe um tempo excessivo e, por exemplo, com editores em vários locais do Brasil já ocorreram ações trabalhistas que, depois de demitidos, ganharam muito dinheiro em razão da carga horária excessiva de 


\section{REVISTA PAUTA GERAL}

\section{ESTUDOS EM JORNALISMO}

10.5212/RevistaPautaGeral.v.6.i2.00014

quem cumpriu durante 10,20 ou 30 anos.

Pauta Geral (PG): Isso me parece que vai ao encontro de outra problemática atual que é a crise passada pelo modelo de negócio do jornalismo, ou seja, há um enxugamento das redações. Ligado a esse raciocínio que você já estava fazendo, mais essa questão, como que você está analisando essa dinâmica e como que a mulher jornalista fica dentro desse cenário?

MJB: Bem, o professor Felipe Pontes ${ }^{2}$ me disse que em Santa Catarina, eles atuaram na pesquisa "Perfil dos Jornalistas", e que as mulheres são mais atingidas por essa crise do modelo de negócio, ou seja, que houve mais demissão de mulheres. Eu disse que

\footnotetext{
2 Felipe Simão Pontes é professor da PósGraduação e do Departamento de Jornalismo da Universidade Estadual de Ponta Grossa (UEPG). Professor do Programa de Pós-Graduação em Ciências Sociais Aplicadas da UEPG. Atua principalmente nos seguintes temas: História da pesquisa em jornalismo, teoria e metodologia em jornalismo e comunicação, história do jornalismo e da comunicação, comunicação em saúde e sociologia da profissão (Informações Lattes. Acesso:07/10/2019).
}

pela $\mathrm{RAIS}^{3}$ e pelo $\mathrm{CAGED}^{4}$, os dados oficiais do Governo Brasileiro, a gente não notava essa discrepância entre demissões de mulheres e homens, era uma coisa mais ou menos homogênea. O número de mulheres demitidas seria próximo do número de homens e o número de mulheres readmitidas também próximo dos homens, mas nos últimos anos houve sim uma perda de postos de trabalho, ou seja, houve muito mais demissões do que admissões. Mas, segundo o professor Felipe Pontes [a crise] atingiu mais mulheres, mas tem um aspecto que vai ter que ser considerado, pois estão surgindo novos polos de produção em jornalismo. Algo que nós havíamos tentado no final da década de 1970 e início da década de 1980, que eram as cooperativas, agora estão voltando. Essas cooperativas são de trabalho e estão colocando os jornalistas e as jornalistas numa relação de maior igualdade, porque todos são cooperados, todos com os mesmos deveres, todos com os mesmos direitos. Estão surgindo também os grupos de produção em jornalismo que estão se organizando de forma independente, normalmente se chama de coletivos e que a gente precisa

3 Relação Anual de Informações Sociais (RAIS).

4 Cadastro Geral de Empregados e Desempregados (CAGED). 


\section{REVISTA PAUTA GERAL}

\section{ESTUDOS EM JORNALISMO}

10.5212/RevistaPautaGeral.v.6.i2.00014

fazer o debate, porque vai ter que haver uma discussão sobre como que esse trabalho vai remunerar o profissional. É maravilhoso que estejam surgindo esses coletivos, mas muitos estão atuando de forma militante e para nós, isso é preocupante porque nós entendemos que o jornalismo é fundamental e que ele deve ser praticado por jornalistas e que 0 profissional tem que ter condição de viver do seu trabalho, ele não pode ter que se preocupar com outra fonte de renda pra garantir a sua sobrevivência e ao mesmo tempo fazer um trabalho voluntário pra exercer o jornalismo. Então é um aspecto que precisa ser amplamente discutido e pra nós só tem um jeito, nós precisamos, nós que eu falo da Federação dos Jornalistas, nós precisamos discutir formas de financiamento da produção jornalística, essas formas de produção não podem estar assentadas só na publicidade que é dos veículos tradicionais, sempre foi assim, com o agravante de que essa publicidade quase sempre é majoritariamente oficial, ou seja, dinheiro público ali empregado. Nós temos que ver como é que o Estado Brasileiro participa desse financiamento, porque nós entendemos que é direito do cidadão à informação, então o Estado Brasileiro tem sim que participar do financiamento. Agora, o que nós precisamos é discutir como isso pode ser democratizado e a gente precisa envolver a sociedade no debate, ou seja, a sociedade precisa entender que 0 jornalismo é necessário e que custa. A internet disseminou uma falsa ideia de gratuidade, que é muito prejudicial para as profissões e é muito prejudicial pra nós jornalistas, porque essa abertura de acesso é extremamente positiva e nós não queremos que ela seja restrita, mas nós também precisamos discutir as formas de financiamento. Eu estou dando sempre o exemplo que eu acho que é o sonho de todo jornalista que é o exemplo do [jornal independente] francês do Mediapart, eles estão conseguindo uma coisa que ninguém havia conseguido que é uma produção jornalística totalmente desvinculada da publicidade. Eles não aceitam publicidade, nem mesmo a publicidade oficial é financiada integralmente pelos leitores e agora espectadores.

Pauta Geral (PG): Isso acaba por reforçar um valor muito caro para o jornalista, que é a própria autonomia?

MJB: Sim, aí você tem, inclusive, essa desvinculação com a publicidade. Você tem uma total independência daquele veículo na produção jornalística, e que 


\section{REVISTA PAUTA GERAL}

\section{ESTUDOS EM JORNALISMO}

10.5212/RevistaPautaGeral.v.6.i2.00014

essa independência do veículo garante uma maior autonomia para o profissional. O que ocorre no sistema da publicidade? A gente tem dois vetores pressionando a produção jornalística: um vetor é o político, que está sempre ali, então, nós somos sempre tensionados como jornalistas pelo poder político constituído e pelo poder econômico, porque como está centrado na publicidade, um anunciante significativo dificilmente vai ser denunciado por uma empresa jornalística. Então, ao se desvincular totalmente da publicidade, esse grupo francês [Mediapart] está conseguindo uma independência editorial que eu creio que jamais houve na história do jornalismo e que pode servir de exemplo para o mundo.

\section{Pauta Geral (PG): Outro assunto muito} discutido aqui no nosso encontro e que também tem sido recorrente o comentário com coletivos de jornalistas mulheres, que fazem jornalismo com perspectiva de gênero, é a questão do assédio às jornalistas. Como a Fenaj pode instruir as mulheres jornalistas e também falar um pouco sobre esse aspecto que tem várias manifestações?
MJB: A primeira coisa é tomar cuidado de não usar o termo "assédio" genericamente. Nós temos dois tipos de assédio tipificados na legislação brasileira, que é o assédio moral, o qual é 0 assédio caracterizado nas relações de trabalho, e temos o assédio sexual que está também caracterizado nas relações de trabalho, mas que extrapola essa relação, ou seja, não precisa estar no mesmo ambiente de trabalho pra haver $\mathrm{o}$ assédio sexual. Então, o assédio moral ligado ao ambiente de trabalho, isso vale pra jornalistas e pra qualquer trabalhadora, é preciso constituir provas. A primeira orientação: você tem que constituir provas, mesmo que isso te custe um pouco, porque é claro que o assédio moral desestabiliza emocionalmente a vítima, mas a vítima precisa, se tiver condições no seu próprio ambiente de trabalho, buscar apoio, inclusive pra se sustentar emocionalmente e constituir provas e denunciar. $O$ assédio sexual está tipificado como crime e aí tem que ser denunciado como crime, é difícil? É! É difícil porque também é uma violência que é objetiva, mas que tem o caráter subjetivo muito grande, principalmente num país machista como o Brasil, num país em que ainda os homens acham que é uma valorização da mulher 


\section{REVISTA PAUTA GERAL}

\section{ESTUDOS EM JORNALISMO}

10.5212/RevistaPautaGeral.v.6.i2.00014

assediá-la. Agora, as agressões das fontes às jornalistas, a gente tem que qualificá-las da forma como a legislação brasileira possibilita. Nós classificamos como agressão verbal e colocamos isso nas nossas denúncias e nos nossos relatórios como agressão verbal, porque aí a gente consegue tipificá-las num dos crimes de opinião da legislação brasileira. O profissional está sendo injuriado ou caluniado ou difamado, praticamente toda agressão verbal, que muita gente está chamando de assédio, você pode enquadrar em um desses três crimes de opinião, ou calúnia, ou injúria ou difamação. Nossa orientação é sempre a denúncia pública, mas também a denúncia formal para instauração de processo pra que aquela pessoa seja responsabilizada e punida. As pessoas têm que passar a ser punidas pelos seus atos de agressões que tem causas muito efetivas na vida das vítimas.

Pauta Geral (PG): Você já passou por vários anos e gestões da Fenaj. Nesses anos, o que você observa de mudanças e de ações pra gente caminhar para uma igualdade de gênero no jornalismo?

MJB: Não é uma coisa simples e não é uma coisa que dependa só da organização profissional. A desigualdade de gênero está arraigada nas sociedades, então como eu disse e gosto de enfatizar isso, é determinante, começa com a educação sexista, então, não é que as mulheres admitem que meninas vestem rosa e meninos vestem azul, mas as mulheres admitem que meninas ganhem bonecas e panelinhas e pias e fogãozinho e etc, e as mulheres presenteiam as suas filhas só com bonecas, panelinhas, xicrinhas, fogãozinho e etc. Essa educação desigual coloca a mulher numa condição de subordinação cultural. Isso está muito arraigado na sociedade brasileira, assim como os meninos recebem a educação sexista contrária, que eles têm que ter a força, que eles têm que dominar as máquinas, que eles precisam estar preparados pra outro tipo de ação. Em paralelo a educação sexista vem a divisão sexual do trabalho. Então é comum ainda hoje que nas casas mesmo de classe média, as filhas tenham tarefas e os filhos não. Assim, vêm as mulheres achando natural elas terem determinadas obrigações que homens não têm e, aí, eu coloco também a organização do ambiente de trabalho que há uma transferência do cuidado doméstico para o ambiente de trabalho. E a mulher acaba achando que é consequência da 


\section{REVISTA PAUTA GERAL}

\section{ESTUDOS EM JORNALISMO}

10.5212/RevistaPautaGeral.v.6.i2.00014

opção dela pela família e as desigualdades que vão ocorrendo no trabalho, então ela não coloca criticamente que ela está sendo vítima novamente. Ela coloca como se fosse uma consequência, uma condição, "como eu não posso deixar de cuidar da minha família eu não vou ser promovida, porque eu não tenho tempo", "como eu às vezes pego um atestado pra acompanhar meu filho isso causa um estranhamento com a chefia", e ela acha que tudo isso faz parte da natureza humana, do cuidado, que a mulher é educada pra cuidar do filho, cuidar do marido, depois cuidar dos pais idosos, cuidar de todo mundo e isso naturaliza algo que é um construto social.

Pauta Geral (PG): Mas você acha que o jornalismo pode ser um instrumento de mudança social ou, pelo menos, para levar conhecimento para que as pessoas reflitam sobre as condições de gênero?

MJB: Deveria ser. O jornalismo, eu falo que é a atividade da crítica por excelência, e a sociedade até nos estigmatiza por isso, que jornalismo só fala coisa ruim. Não, o jornalismo é uma atividade da crítica, nós temos que apontar os problemas sociais e também apontar as soluções para aqueles

problemas

sociais. Nós

temos que

denunciar,

nós temos

que de

alguma

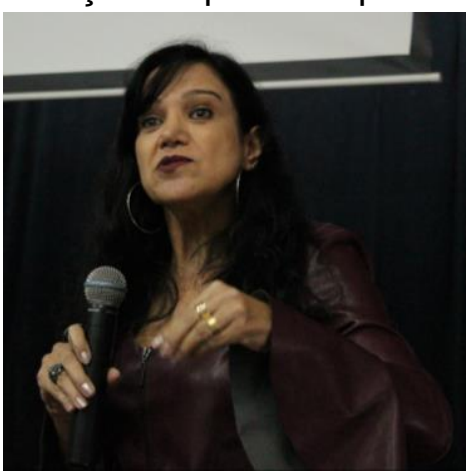

forma contribuir pra que o cidadão e a cidadã passem a ter uma atuação cidadã e por que não fazer isso com as questões de gênero? É um problema social, não é um problema só de gênero, é um problema que está muito presente na vida pessoal, mas que extrapola a vida pessoal, isso vai pra vida social, isso vai pra atuação política, pra atuação profissional. Então, é um problema da sociedade e, por isso, tinha que ser tratado pelo jornalista como um problema da sociedade, e não é. Primeiro porque não é culpabilizando as mulheres, mas a gente tem que realmente reforçar essa formação das mulheres para que o machismo seja derrubado, obviamente, a partir das mulheres. É igual à classe trabalhadora e os privilégios do capital, só irão ser derrubados a partir da organização das classes trabalhadoras. Quem está lá em cima não vai querer mudar. Claro que existem homens muitíssimos comprometidos com as igualdades, com as liberdades, mas essa 


\section{REVISTA PAUTA GERAL}

\section{ESTUDOS EM JORNALISMO}

10.5212/RevistaPautaGeral.v.6.i2.00014

desconstrução do machismo só vai ser feita a partir das mulheres, e para as mulheres fazerem isso elas precisam se libertar dessa reprodução que é feita cotidianamente das formas mais sutis possíveis e que muitas vezes nós não percebemos. Então as mulheres se tornaram maioria no jornalismo, mas isso ainda não fez diferença, a não ser questões pontuais como o surgimento de publicações com enfoque de gênero, 0 surgimento de publicações pra públicos específicos como mulheres intelectuais, como mulheres gays, mas o que chamamos de comunicação de massa não teve um impacto, não tem nem ensaio nos meios de comunicação para o grande público. Nós não temos nem ensaio do que seria um jornalismo com perspectiva de gênero, então são experiências que nós não tivemos. Não é só no Brasil, isso é muito presente em praticamente todos os países do mundo, as fontes são prioritariamente masculinas, porque o jornalismo é muito ligado ao poder. As fontes são geralmente as fontes oficiais de poder. A mulher é tratada de forma diferenciada nas abordagens, nos assuntos e como é procurada e etc. É um trabalho que a gente fala que é necessário o tempo todo, mas nós ainda não conseguimos nos organizar para pelo menos tentar implementá-lo como experiência. Eu acho que não existe uma experiência de um veículo de comunicação geral, desses tradicionais, que faça jornalismo ou que tenha tentado fazer jornalismo com a perspectiva de gênero, estamos longe disso.

Fotos: Rafael Bahls, Maria Eduarda Eurich e Larissa Onorio

Recebido em: 15/10/2019

Aprovado em: 04/11/2019 